https://helda.helsinki.fi

\title{
An Assessment of How Scientific Literacy-Related Aims Are Actualised in the National Primary Science Curricula in China and Finland
}

Wang, Yan

2019-05-01

Wang , Y , Lavonen , J \& Tirri , K 2019 , ' An Assessment of How Scientific Literacy-Related Aims Are Actualised in the National Primary Science Curricula in China and Finland ', International Journal of Science Education , vol. 41 , no. 11 , pp. 1435-1456 . https://doi.org/10.1080/09500693.2019

http://hdl.handle.net/10138/304329

https://doi.org/10.1080/09500693.2019.1612120

Downloaded from Helda, University of Helsinki institutional repository.

This is an electronic reprint of the original article.

This reprint may differ from the original in pagination and typographic detail.

Please cite the original version. 


\begin{abstract}
This research compared how the scientific literacy-related goals of the current Chinese and Finnish national science curricula at primary school level are actualised using a revised Programme for International Student Assessment (PISA) scientific literacy framework in the content analysis of the curricula. The content of the curricula focuses principally on knowledge, followed by competencies and attitudes, respectively. The learning context was seen to be thoroughly integrated with the content in both countries. However, the curricula are writte in different ways. Generally, the literacy objectives for both curricula are based on scientific knowledge (Vision I) and the application of knowledge-based skills in situations (Vision II). However, they are characterised by implicit views that derive from the pursuit of the value-driven transformation of individuals and society achieved through science education (Vision III). The Chinese curriculum appears to favour the Anglo-American tradition, whereas the Finnish curriculum appears to be more attached to the Bildung-Didaktik tradition in terms of core tasks and the specification of objectives. The recommendation is that Vision III should be included in the science curricula, and should explicitly relate to social and scientific topics with a view to furthering a scientifically literate public. Keywords: science curriculum, scientific literacy, PISA, China, Finland
\end{abstract}




\section{An Assessment of How Scientific Literacy-Related Aims Are Actualised in the National Primary Science Curricula in China and Finland}

Introduction

The term 'scientific literacy' (SL) is a widely recognised educational concept and has become a key educational goal (De Boer, 2011; Hodson, 2011). SL is a major component of the national curriculum in various countries, helping to accelerate the globalisation of science education (De Boer, 2011; Hodson, 2011; Roberts \& Bybee, 2014). However, it has been suggested that SL is merely an interesting term in national policy documents rather than a consistent and deliberately chosen goal (De Boer, 2011; Sadler \& Zeidler, 2009). SL may also be interpreted as having different emphasis in differing curricula owing to its complexity and evolution (Roberts, 2007). A growing number of studies has discussed the relationship between the objectives of SL and its focus on curriculum design (De Boer, 2011; Sjöström, Frerichs, Zuin \& Eilks, 2017). According to Fensham (2009, p. 1076), '[Educational] policy has been a muchneglected area of research in science education'. To the best of our knowledge, only a very few studies have analysed a national curriculum to determine the actualisation of SL.

A national curriculum is used to achieve the intended educational goals at the national level and guides and regulates educational processes (Oliva, 1997). Whilst teaching practices could be more direct about learning outcomes, the failure of educational reform may be owing to ambiguous meanings in formal teaching documents (such as curricula), as well as the methods and practices used (Bergqvist \& Bergqvist, 2017; Cuban, 2013; Fullan, 2001). Moreover, a national curriculum is not a neutral assemblage of knowledge; instead 'it is produced out of cultural, political and economic conflicts, tensions and compromises' (Apple, 1993, p.1). Neoliberalism, a complex economic and social phenomenon, together with globalisation and 
capitalism, has influenced education. Specifically, in science education, the suggestion is that emphasis has been placed on 'individual achievement over the common good and consumption, while underemphasising, depoliticising and naturalising the role of corporations, market logic and private interests in science' (Bazzul, 2012, p. 1004). In an era of worldwide neoliberal educational reforms, outside influences and global governance are unavoidable. Nevertheless, traditions that are embedded in the curricula are difficult to change (Cuban, 1992). Finland and China are useful cases for comparison as they are associated with high academic performance and achievement in international assessments such as the Programme for International Student Assessment (PISA) (Organisation for Economic Co-operation and Development [OECD], 2016), despite having different educational traditions (Autio, 2014). The current research examines how SL is translated and actualised in the National Primary Science curricula of Finland and China in relation to different SL visions and educational traditions.

\section{Three visions for SL analysed in relation to the PISA}

Since the 1950s, SL has been used and developed from a simple slogan into a soughtafter goal in science education (Roberts, 2007). A number of researchers have discussed its definition and components. Roberts (2007) summarised and proposed two visions for teaching SL. The first (Vision I) decrees that SL is science-orientated, and the focus is on teaching canonical subject matter and acquiring natural science knowledge. The second (Vision II) advocates the application of literacy in science-related situations. The two visions are characterised by major tension over whether the curricular emphasis should be on the acquisition of scientific subject matter or knowledge, or on the application of scientific knowledge and competencies in real-life contexts. Usually, it is assumed that a modern science curriculum should integrate the two approaches (Roberts \& Bybee, 2014). 
In recent decades, researchers have argued that science and research in science are not value-free and that science education should pay particular attention to the cultivation of citizens who will actively and reflectively engage in social and political issues (Bazzul, 2012; Hodson, 2003; Levinson, 2010). Sjöström et al. (2017) proposed an additional vision (Vision III), whereby science education should be connected to the Bildung tradition. The latter is critical and reflexive, embracing the pursuit of critical knowledge, value consciousness, ethics and responsibility. The objective of Vision III is social-political engagement in pursuit of the valuedriven transformation of both individuals and societies whose goal is emancipation beyond the objective of preparing citizens for a technological society (Vision II) (Sjöström et al., 2017).

In summary, the three different visions for SL place different emphasis on what is important in a science curriculum. Vision I (the knowledge-based approach) highlights the importance of scientific knowledge (content and procedural). Vision II (the contextual approach) emphasises the usefulness of utility and the meaningfulness of science (including technology and engineering), while striving to contextualise science teaching and learning. Vision III (the critical approach) stresses the value of teaching and learning science as a means of achieving the transformation of individuals and society. Specifically, it encourages political action or participation in socio-scientific issues (SSIs) (Sjöström et al., 2017).

According to PISA, SL is defined as 'the ability to engage with science-related issues and with the ideas of science as a reflective citizen' (OECD, 2013, p. 7). As argued by Sadler and Zeidler (2009), even if the test items do not fulfil the intent behind the SSI movement, the PISA framework, with its focus on SL, aligns well with the SSI approaches. In addition, the 'reflective citizen' seems, at least implicitly, to pertain to Vision III. In general, the PISA definition of and framework for SL are consistent with Vision II, while factoring in Vision III. In principle, the 
PISA definition and framework fits with an understanding of SL in the present research and achievement of its objectives. Thus, the PISA definition and framework were applied in the current study.

\section{Bildung-Didaktik and Anglo-American Curriculum Theory}

The Anglo-American curriculum theory and European-Scandinavian Bildung-Didaktik are two major theories of curriculum in 'Western countries' (Autio, 2014; Westbury, 2000). Typically, the Anglo-American curriculum tradition specifies what a student should be able to do, while the subject matter focuses on performance and outcomes (Autio, 2014; Pantić \& Nataša 2012; Westbury, 2000). The intended curriculum and teaching plans are usually wellarticulated, and concrete objectives are outlined. The idea is to direct the instruction explicitly. Teachers are trained and certified and are also assessed against student learning outcomes according to a standardised curriculum (Autio, 2014; Westbury, 2000). The logic behind this tradition aligns with the US reform model of accountability, standardisation and 'teaching-to-thetest' (Autio, 2014).

The Bildung tradition encompasses a broader meaning than merely education or learning. In contrast to an output-orientated approach, which begins by predicting what will be useful in the future and goes on to prepare the student for that, the aim of the Bildung tradition is to shape the learner as an individual, contribute to the development of his or her full potential and promote independent decision-making (Willbergh, 2015). The Bildung-Didaktik tradition involves respect for teachers' pedagogical freedom and autonomy and highlights the discourse between the teacher and students during the lesson (Hopmann, 2007; Westbury, 2000). Although a lehrplan (literally, a teaching plan) is followed, it typically only includes a set of guidelines with goals or directives. The teachers are considered to be autonomous experts, with the freedom 
to adopt their own approaches and select the subject matter within the framework of an illustrated lehrplan. Such a plan is only considered to be meaningful and educational when it is interpreted by qualified teachers (Autio, 2014; Hopmann, 2007). Successful teaching is demonstrated through the professional appropriateness and reflections of the teacher, rather than solely through the students' learning outcomes (Pantić \& Wubbels, 2012; Westbury, 2000).

In general, the Anglo-American tradition regards the curriculum as a course of action with relatively complete content, specification and instructions that are used to achieve standardised learning outcomes in particular subject areas (output), whereas the BildungDidaktik tradition views the intended curriculum (lehrplan) as a frame of reference with limited detailed content (usually topics) and is characterised by reliance on the teachers' professionalism (input) and a concern for the transformation of individuals and society beyond a specific subject per se. The stances are primarily concerned with teaching and learning goals in education, and, in some respects, have merged through increased interaction and international influence. The extremes of a continuum are referred to this research, and the argument is built on the differences.

\section{Background to Educational Science in Finland and China}

Given the national and international educational reforms that have taken place since 1921, the Finnish curriculum is now a mix of the Anglo-American and Bildung-Didaktik curricula (Autio, 2014; Saari, Salmela \& Vilkkilä, 2014). Historically, Finland adopted the spirit of the Bildung tradition inherited from a philosophical German approach, justified and made popular by Snellman (Autio, 2014; Saari et al., 2014). After the Second World War, American educational psychology was introduced to Finland and was gradually integrated into the educational system in the Finnish context (Saari et al., 2014). The educational system in Finland 
was decentralised in the 1980 s, meaning that most decision-making concerning the organisation and content of general education was transferred from the state to municipalities, and even further down to individual schools (Niemi, Toom, \& Kallioniemi, 2016). Within a decentralised educational system, Finnish teachers have the autonomy and freedom to organise their classes in the way that they want and choose the content and teaching materials, i.e., textbooks. The national curriculum works as a guideline for the teaching process rather than as a set of requirements with detailed objectives. According to Saari et al. (2014), after the Cold War, the approach to the school system in Finland changed to a capitalist market model. Emphasis was placed on economic and global competitiveness, and this is reflected in the educational policymaking and curriculum planning.

The Finnish national curriculum is revised every 10 years. The most recent revision was published in 2014 (Finnish National Board of Education, 2016). The new primary science curriculum (hereafter referred to as FIN-PSC) is part of the national core curriculum for basic education, and is integrated into one document together with other subjects. In Finnish primary schools, science is referred to as 'environmental studies' and is taught by a class teacher for two lessons a week (45 minutes per lesson) in Grades 1-2 (7-8 years) and on average for 2.5 lessons a week in Grades 3-6 (9-13 years). The development of the whole person is emphasised in the Finnish educational system. All the school subjects are regarded as equal (Sahlberg, 2015).

It is generally argued that the approach to curriculum theory in China is a unique combination of Western theories. Prior to 1989, systematic work was not conducted on approaches to curriculum theory. Tracing ancient Chinese wisdom traditions (Confucianism, Taoism and Buddhism) to develop a uniquely Chinese curriculum theory only took place recently (Zhang \& Gao, 2014). Contemporary Chinese curriculum theory has taken cues from 
the USA, Soviet Union and other countries, i.e., Japan (Zhang \& Gao, 2014). The Chinese science curriculum was significantly impacted by the Anglo-American curriculum from 1990 (Ding, 2015). The current research does not deliberate the science curriculum in relation to traditional Chinese wisdom because elucidation of the influence of the latter on the development of curriculum theory has been vague and is complex, specifically as research in this field was only conducted recently and remains insufficient. This approach also facilitates a simplification of the comparison of educational traditions with Finland.

Chinese education is more centralised than that in Finland although efforts have been made to modify this through educational reforms (Law, 2014). The Chinese Ministry of Education is the highest authority responsible for the planning and designing the national curriculum. Using clear objectives, it directs teaching practices in schools. Typically, teachers faithfully follow the national curriculum objectives and use the recommended materials.

The primary science curriculum in China is an independent document that exists in parallel to curriculum documents for other subjects. The Chinese national curriculum (the experimental version) was officially published in 2001, revised in 2011, and thereafter a newly revised version for primary science (hereafter referred to as CH-PSC) was officially published (in 2017). The intention of the recent educational reforms in China was to change the narrow perspective held of knowledge transmission via classroom instruction so that students can develop positive attitudes and key competencies while learning science (Author(s), year; Ding, 2015; Tao, Oliver \& Venville, 2013). Traditionally, learning science in primary schools has not been considered as important as learning Chinese language and mathematics. Yet, from autumn 2018, primary science education (two lessons a week, 45 minutes a lesson) became compulsory 
for Grades 1-6 (6-12 years), alongside implementation of the new national primary science curriculum.

Thus, the research questions in the current study are (1) How have the objectives of SL been specified in the framework of PISA Science Framework in the two curricula? (2) What are the similarities and differences between the two curricula regarding the implementation of SL objectives in terms of the three visions for a science curriculum design and the two approaches to curriculum theory?

\section{Methods}

Using an analytical framework with a focus on SL, the present research examined how SL is embodied in the current FIN-PSC and CH-PSC. The CH-PSC comprises 89 pages and 62,601 words, of which 51 pages [36,909 words] are devoted to practical teaching suggestions and assessments. By contrast, the FIN-PSC consists of 13 pages [6,256 words], of which four pages [2,134 words] are reserved for practical teaching suggestions and assessments. The content was analysed, with the exception of that relating to practical suggestions for instructional and assessment methods in the curricula. The original English version of the CH-PSC was translated by the first author, while the English version of the FIN-PSC was officially translated by the Finnish National Board of Education (2016). The quotations cited in this paper were taken from translations of the curricula and paraphrased for the sake of clarity.

The method used was deductive content analysis, previously described by Weber (1990) and Mayring (2015). The category definitions within the 2013 PISA science framework were identified. The PISA framework was applied because it articulates the meaning of SL and separates SL objectives according to domains (Harlen, 2001; Bybee \& McCrae, 2011). The PISA science assessment is widely applicable to the teaching of science and involves the application of 
scientific knowledge in real-life contexts (Britton \& Schneider, 2014; Bybee \& McCrae, 2011; Roberts \& Bybee, 2014). It aims to produce scientifically literate adults without making schoollevel divisions. The framework was a useful operational tool to use to compare the two curricula.

Pilot tests were carried out to evaluate and revise the categories and their definitions because the PISA framework does not include all possible definitions and some of them were ambiguous. During the revision process, units that were difficult to code were subject to deliberation to ensure clearer descriptions of the categories (codes) and to make sure that the coding practices were more systematic. Continual checks were performed during the pilot tests until consensus was reached. The text was coded once agreement was reached regarding the final version of the coding agenda (analytical framework). Details of the coding process, together with examples, are provided in the next section.

The observed frequencies and intragroup percentages of the units were calculated for each code (Tables 1-7). The chi-square test $\left(\chi^{2}\right)$ was used to test the hypothesis that the FIN-PSC and CH-PSC differ in their emphasis on certain aspects of SL. Additionally, the frequencies with which the term 'scientific literacy' appeared in each curriculum were counted.

\section{Coding}

Scientific competencies are defined as the key abilities of scientifically literate persons manifested in specific science-related contexts, and are dependent on scientific knowledge and attitudes to science (Bybee \& McCrae, 2011; Harlen, 2001; OECD, 2013). Figure 1 illustrates the four categories and subcategories identified using the revised analytical framework. 
Figure 1 Analysis Framework

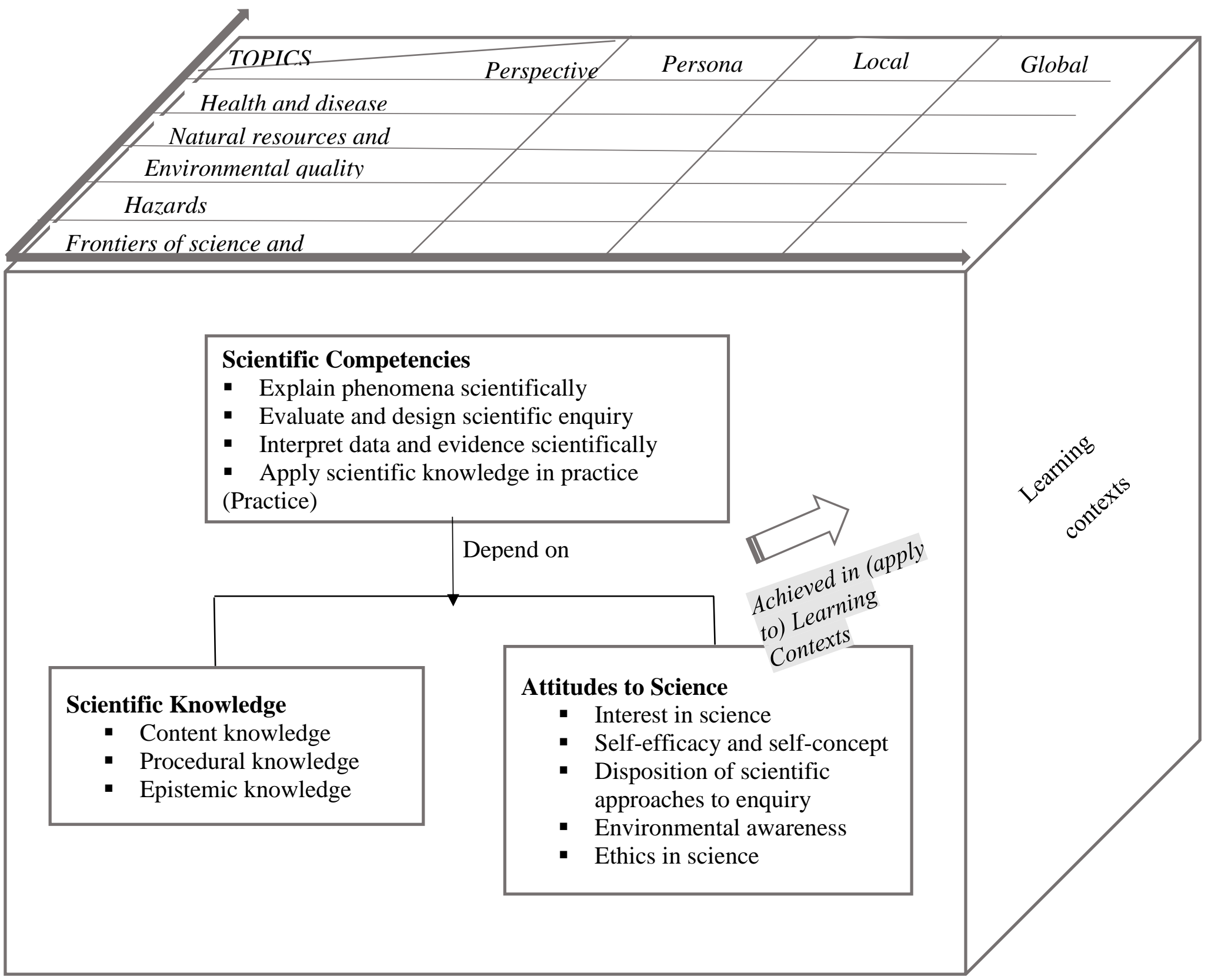


Coding was applied to identify the coding units and appropriately position each unit in a code. The coding units were not strictly limited to a single word or sentence. Each unit included one idea. The noun and the verb in each item were carefully considered as the former usually provides the basis for the knowledge dimension and the latter, the competencies dimension (Krathwohl, 2002). However, there were exceptions. For example, verbs such as 'know' and 'understand' were not coded in the competency-based categories, but rather in scientific content knowledge categories.

\section{Category 1: Scientific competency.}

The original PISA framework refers to three key competencies (explain, enquire and interpret) that involve the need to (1) explain the phenomena scientifically, (2) evaluate and design a scientific enquiry and (3) interpret the data and evidence scientifically (OECD, 2013). A fourth (practise), i.e., apply the scientific knowledge in practice, was added in the current study because the objectives of primary-level science education are not only to develop the cognitive abilities of students, but also to promote the basic habits of rational living (Holbrook \& Rannikmae, 2007; Roth, 2014). The fourth code was assigned when the text referred to the ability to apply scientific knowledge to hands-on work and to transfer the rationale learnt in science to daily life; for example, the ability to make personal decisions about health, and ideally gain an understanding of the complexity of everyday technologies, science and culture, supported by democratic and cultural justification of the science.

Examples of scientific competency are provided below. The identified units are underlined. The codes are italicised at the beginning of each example: 
Explain: '[Teachers should] guide the pupil to explore, describe, and explain the physical phenomena encountered in daily life, nature and technology...' (FIN-PSC, p. 7).

Inquiry: '[Students should learn to] observe and describe the basic characteristics of objectives and the properties of materials' (CH-PSC, p. 5).

Interpret: 'The multidisciplinary nature of environmental studies requires that pupils learn to acquire, process, produce, present, evaluate and appraise information in different situations' (FIN-PSC, p. 1).

Practices: '[Students learn to] use common materials to make simple tools' $(\mathrm{CH}-$ PSC, p. 37).

\section{Category 2: Scientific knowledge.}

'Scientific knowledge' refers to a basic understanding of science from a cognitive perspective (Ryder, 2001). 'Content knowledge' is knowledge of science and awareness of the facts, concepts, ideas or theories that science has established about nature. This research deliberately separated content knowledge into four domains, i.e., physical systems, living systems, earth and space systems, and technology and engineering systems, rather than into traditional academic subjects for two reasons. Firstly, the use of 'systems' is in line with an understanding of SL - to contextualise the learning of science - in the current research, thus conveying the idea that the knowledge that is applied to real-life practices is typically interdisciplinary (OECD, 2013). Secondly, this research concerned primary level curricula, for which a clear demarcation between disciplines is not yet apparent. Specifically, primary science is an integrated subject in both countries, and includes physics, chemistry, biology, geography 
and technology. Therefore 'systems' fits better than other codes used to describe purely academic subjects, such as physics.

'Procedural knowledge' refers to how science is carried out; it involves awareness of the methods used by scientists to establish what is known, as well as the procedures used by technologists and engineers to design machines (OECD, 2013). Given the influence of neoliberal ideology on society, students need to understand not only how and why it is important to hold a supportive perspective of science, but to also realise that science, if seen as a social institution, is not all-powerful, all-knowing, totally objective or value-free; science too can reflect biases and be restrained by particular contexts (Hodson, 2011; Ziman, 2000). For example, scientific studies may be driven by capital. Here 'science' is used as a general term and includes technology and engineering. Bringing critical views to bear on science is significant. Epistemic knowledge is required as a sufficient in-depth understanding, or at least awareness, of science and its relevance. 'Epistemic knowledge' is defined as 'knowledge of the constructs and defining features essential to the process of knowledge building in science and their role in justifying the knowledge produced by science and its role in contributing to how we know what we know' (OECD, 2013, p. 20).

Examples of scientific knowledge are provided below. The identified units are underlined. The codes are italicised at the beginning of each example:

Physical systems in content knowledge: '[Students should] know the basic properties of matter and different forms of motion' (CH-PSC, p. 5).

Living systems in content knowledge: '[Teachers should] guide the pupil to understand the structure, vital functions and development of humans' (FIN-PSC, p. 7). 
Procedural knowledge: '[Students should learn to] draw up a concrete research proposal' (CH-PSC, p. 7).

Epistemic knowledge: '[Students should] understand that scientific knowledge changes with new scientific discoveries and is not constantly stable; with new evidence old scientific knowledge can be deepened and renewed' (CH-PSC, p. 6).

\section{Category 3: Attitudes to science.}

This category included five subcategories (codes). 'Self-efficacy or self-concept' and 'ethics in science' were added to the original three subcategories provided in the original PISA framework. The five codes covered two views; attitudes towards learning science and attitudes towards science in general.

The first view refers to individual feelings and beliefs about learning or exploring issues that relate to science topics (e.g., SSIs). 'Interest in science' is a set of feelings associated with studying or doing things in or related to science (including technology and engineering) (Bybee \& McCrae, 2011; OECD, 2013; Osborne, Simon \& Collins, 2003). 'Self-efficacy or selfconcept' refers to confidence or a belief in one's ability to perform a scientific task successfully ([Author(s), year]).

The second view denotes the dispositions, beliefs and values held towards science and related issues (e.g., SSIs). 'Disposition of scientific approaches to enquiry' is a rational attitude to the use of scientific methods to investigate material and social phenomena, such as being open-minded and adopting critical thinking (Bybee \& McCrae, 2011; OECD, 2013; Osborne, Simon \& Collins, 2003). In other words, on the one hand, the adoption of a 'rational attitude' refers to recognition of the value of scientific approaches to enquiry, i.e., valuing scientific ways of gathering evidence. On the other hand, it means having an open attitude to received 
information and declared approaches and claims based on the understanding that scientific approaches involve biases and limitations or are influenced or restrained by contexts, such as claims by experts or those in authority. 'Environmental awareness' refers to a concern for and responsible disposition towards the environment. 'Ethics in science' is critical awareness of and reflection on scientific research and applications (DeBoer, 2000; Donnelly, 2006). Science is part of culture and relates to moral emotions, and social and political contexts (Hodson, 2011; Ziman, 2000). 'Ethics in science' concerns the importance of how facts and values interact, critical views on SSIs, and democratic participation in social and political issues, i.e., the use of embryos in research (Hodson, 2011; Levison, 2010).

Examples of attitudes to science are provided below. The identified units are underlined. The codes are italicised at the beginning of each example:

Interest in science: 'Students should be curious about natural phenomena and remain passionate about enquiry' (CH-PSC, p.8).

Self-efficacy or self-concept: '[Teachers should] guide and encourage the pupil to set personal study goals and make persistent efforts to achieve them, and recognise his or her own competence in environmental studies' (FIN-PSC, p. 6). Disposition of scientific approaches to enquiry: 'Students should develop an awareness that they must present their ideas based on evidence and proper reasoning' (CH-PSC, p. 8).

Environmental awareness: '[Teachers should] support the development of the students' environmental awareness' (FIN-PSC, p. 2).

Ethics in science: 'Students should know that in science and technology research and application, ethics and moral issues should be considered seriously' (CH-PSC, p. 9). 


\section{Category 4: Learning contexts.}

Generally, learning contexts refer to a set of backgrounds or situations in which an activity is planned that may influence students' interests and educational outcomes (Hodson, 2003; Holbrook \& Rannikmae, 2007; Osborne \& Collins, 2001; Osborne, 2007). The learning context was measured in the current study against topics and perspectives; assigned when the text indicated a learning science background. 'Topics' that were closely related to SSIs were classified using five codes, for example, two of which were 'health and disease' and 'natural resources and technology'. The three codes of 'perspectives' were 'personal', 'local' and 'global'.

Examples of learning contexts are provided below. The identified units are underlined. The codes are italicised at the beginning of each example:

Natural resources and technology and global: "[Students should] understand the limit of the resources on earth and realise that our activities have both positive and negative effects on the environment' (CH-PSC, p. 9).

Personal: '[Teachers should] guide the student to explore, describe and explain physical phenomena in daily life...' (FIN-PSC, p. 7)

\section{Reliability}

Relatively high reliability was a feature of the current study as the first author is a Chinese doctoral student who is working towards a doctoral degree in Finland, and the second and third authors are Finnish professors whose expertise is in science education and comparative research, respectively. The coders independently coded the text during the coding process. Formative agreement was found to be 0.5 . Summative agreement reached $90 \%$ for the final coding version (Cohen's kappa $=0.84)$. 


\section{Results}

\section{Overview of the Chinese and Finnish Primary Science Curricula}

Overall, the structure and basic content of the CH-PSC and FIN-PSC appeared to be similar. Following analysis, the CH-PSC had 1,486 units belonging to specific categories, compared to 783 in the FIN-PSC. The tasks in both curricula appear to be similar in terms of the need to acquire basic scientific knowledge, producing informed future citizens, protecting the environment and promoting lifelong learning. However, there are differences in the rationale and regarding the emphasis that is placed on core tasks. The beginning of the CH-PSC reads 'With the development of science and technology, new scientific discoveries and technological creations are emerging every day. Science and technology play an essential role in social and economic development...'. (CH-PSC, p. 1). This suggests that the reason science is taught in Chinese primary schools is because it supports social and economic development.

By contrast, the FIN-PSC has no such description to justify why science is taught at the primary level. One statement seems to indicate its rationale: 'In environmental studies, pupils are considered part of the environment in which they live. Respect for nature and a life of dignity in compliance with human rights are the basic principles in teaching and learning.... Pupils are supported to build a relationship with the environment, develop their worldview and grow as human beings' (FIN-PSC, p. 1). This statement suggests that emphasis is placed on individual development as a consequence of learning science rather than merely viewing students as tools for a country's economic development.

'Scientific literacy' is specified as the core task in the CH-PSC. Generally, 'scientific literacy' means to 'have basic or essential scientific knowledge; know its influence on social and individual life; have basic knowledge of scientific methods; understand the nature of science; 
build up scientific ideas and appreciate the spirit of doing science; be able to apply what [students] know about science to solve practical problems and participate in public affairs' $(\mathrm{CH}-$ PSC, p. 1).

As a term, 'scientific literacy' appears 11 times in the CH-PSC. It does not appear at all in the FIN-PSC, which uses phrases such as 'students' health and well-being' and 'sustainable development' as per this example: 'Environmental studies is an integrated subject comprising the fields of biology, geography, physics, chemistry and health education, and includes the concept of sustainable development.... The objective of the instruction is to guide the students to know and understand nature and the built environment, related phenomena, themselves and other people, as well as the importance of health and well-being' (FIN-PSC, p.1). However, the meaning of sustainable development or well-being has not yet been fully elucidated.

The CH-PSC describes specific objectives and outlines what learners should know or be able to do, thus targeting learning outcomes, for example: 'Students should know how to design a research plan if they want to engage in scientific enquiry' (CH-PSC, p. 6). Teachers are encouraged to follow and check off the tasks shown in a detailed checklist. Sentences in the FINPSC sometimes start with 'pupils' or 'students' to indicate performance expectations, for example: 'The pupils learn about the basic necessities of life in terms of food, water, air, warmth and care' (FIN-PSC, p. 4). Teachers are guided as to what they should do in general, for example: 'Guide the student to analyse the environment, human activities and related phenomena using concepts from different fields of environmental studies' (FIN-PSC, p. 3). The aims are described in general terms rather than clearly pointing to the domain of science. Teachers are provided with guidelines to follow without the provision of specific outcome requirements. 
The subject content objectives are also described in different ways. While both curricula illustrate the themes or core content that recommend being taught, in general, the FIN-PSC lists the 'key content areas' without separating the subjects. For example, in Grades 1-2, key content areas include subheadings such as 'Growth and development', 'Activities at home and school', 'A reflection on the basic necessities of life' and 'The need to practise a sustainable way of living', all of which focus on the interaction between the curriculum content and daily life, and yet objectives are not provided for specific subject areas. Content in the CH-PSC is described both in general and concrete terms, and a list of objectives is provided for scientific subjects under subheadings such as 'physical sciences', 'life sciences', 'earth and space sciences' and 'technology and engineering'. These examples illustrate how 'forces', mentioned in both curricula, have different connotations in each curriculum:

'By examining changes in the movement of objects, students [Grades 3-6] familiarise themselves with the concept of force' (FIN-PSC, p. 8).

'[Students] [Grades 1-6] should know that] forces can change the motion of objects' (CH-PSC, p. 10).

'[Students] [Grades 1-6] should know that] there are a variety of types of forces. Two broad categories [are applied] on the basis of whether the force results from the contact or non-contact of two interacting objectives' (CH-PSC, p. 16).

'[Students (Grades 1-2) should be able to] describe how a magnetic force can affect objects at a distance' (CH-PSC, p. 16).

Mention of 'forces' appears only once in the FIN-PSC under the theme 'Exploring the environment'. By contrast, both specific and general references are made to 'forces' in the $\mathrm{CH}$ PSC in the physical science section. The specification of different objectives for knowledge of a 
subject suggests differences in the emphasis on science education and autonomy by the teacher between the two curricula. The FIN-PSC shows that the learning outcome of understanding and acquiring knowledge of the subject matter, such as the concept of force, is as important as experiencing contextualised activities since it is achieved through a series of enquiries. It provides the teachers with freedom to select the content provided that they adhere to the theme 'Exploring the environment'. The CH-PSC lists the objectives that relate to the concept of force using an explicit discipline, i.e., physics. Emphasis appears to be placed on understanding classic subjects, even though enquiry and the application of knowledge-based skills are stressed in the curriculum.

\section{Distribution of the Main Scientific Literacy Categories}

Both curricula cover the three main categories of SL, namely scientific competencies, scientific knowledge, and attitudes to science (Table 1). Scientific knowledge is the major part of each curriculum in terms of quantity. Scientific competencies are purposefully mentioned in both curricula and are based on two types of evidence. 'Scientific enquiry' in the CH-PSC and 'Research and working skills' in the FIN-PSC are presented separately, and both include objectives for the development of competencies. Competencies are also mentioned in specific content areas that are usually associated with subject knowledge and are described as verbs.

'Attitudes to science' is specified in both curricula.

Examples of scientific competencies and knowledge are provided below.

With the teacher's guidance, students learn to ask questions by observing and comparing the phenomena in which they are interested (Objectives of Scientific Enquiry, CH-PSC, p. 7). 
Students are encouraged to wonder, ask questions and use collaborative discussions as a basis for small research assignments and other activities (Research and Working Skills, FIN-PSC, p. 2).

Describe the characteristics of living things (Content area, CH-PSC, p. 23).

They [the students] learn to recognise the most common species and their habitats, as well as objects in the built environment (Key content area, the FIN-PSC, p. 3).

Examples of attitudes to science are provided below.

Students could be motivated by awakening their curiosity or supporting the development of interest while observing or investigating common scientific phenomena or natural phenomena, such as common plants, animals and materials (CH-PSC, p. 8).

Students are encouraged to enjoy environmental studies (FIN-PSC, p. 2).

Table 1 Categories of scientific literacy

\begin{tabular}{lccc}
\hline Scientific literacy & CH-PSC & FIN-PSC & Total \\
\hline Scientific competencies & $274(23.7 \%)$ & $176(33.2 \%)$ & 450 \\
Scientific knowledge & $756(65.5 \%)$ & $299(56.4 \%)$ & 1055 \\
Attitudes to science & $124(10.8 \%)$ & $55(10.4 \%)$ & 179 \\
Total & 1154 & 530 & 1684 \\
\hline
\end{tabular}

$\chi^{2}(2, N=1684)=16.5, p<0.05$

The differences between the CH-PSC and FIN-PSC regarding the distribution of scientific literacy categories are statistically significant, $\chi^{2}(2, N=1684)=16.5, p<0.05$. The percentage of statements made about attitudes to science is similar ( $\mathrm{CH}-\mathrm{PSC}, N=124,10.8 \%$; FIN-PSC, $N=56,10.4 \%$ ). However, the percentages for the two other categories in each curriculum differs, indicating a difference in emphasis (Table 1). There are fewer statements about scientific competencies in the CH-PSC than those in the FIN-PSC (23.7\% vs. 33.2\%), 
while the CH-PSC includes more units of scientific knowledge in percentage than the FIN-PSC (65.5\% vs. $56.4 \%)$

\section{Different Emphasis on Scientific Competencies}

The two countries demonstrate similar intentions regarding the desire to develop students' competencies in science, but the difference in the distribution of the four competencies across the curricula is statistically significant, $\chi^{2}(3, N=450)=32.8, p<0.05$ (Table 2$)$. The 'explain' competency ranks highest in the CH-PSC, followed by the 'inquiry' competency (49.6\% vs. $29.2 \%$ ). By contrast, the FIN-PSC places more emphasis on the 'inquiry' competency, followed by the 'explain' competency (45.5\% vs. $23.9 \%)$. Verbs such as 'describe', 'explain', 'recognise' and 'provide (examples)' (identified as competencies in the 'explain' domain) appear more frequently in the CH-PSC than 'process' and 'observe' (identified as competencies in the 'inquiry' domain), a stance opposite that of the FIN-PSC. The emphasis on interpretation (the 'interpret' competency) occupies a minor part of both curricula. The low percentage annexed to this competency may relate to the emphasis that is placed on learning at the primary school level. Although the desire to develop scientific skills is evident in both curricula, the objectives of primary science education in both countries appear to be ensuring that the students experience science, develop an interest in it and master basic science knowledge and competencies, rather than focus on higher level competencies, such as data interpretation.

Table 2. Frequency of scientific competencies (percentage)

\begin{tabular}{lccc}
\hline Scientific competencies & CH-PSC & FIN-PSC & Total \\
\hline Explain phenomena scientifically & $136(49.6 \%)$ & $42(23.9 \%)$ & 178 \\
Evaluate and design scientific enquiry & $80(29.2 \%)$ & $80(45.5 \%)$ & 160 \\
Interpret data and evidence & $24(8.8 \%)$ & $12(6.8 \%)$ & 36 \\
scientifically & $34(12.4 \%)$ & $42(23.9 \%)$ & 76 \\
Practices & 274 & 176 & 450 \\
Total & & & \\
\hline
\end{tabular}


Encouraging students to participate in practical work, apply the knowledge learnt in school in daily practice and cultivate habits for transference to daily life is emphasised to a greater extent in the FIN-PSC than in the CH-PSC (23.9\% vs. 12.4\%). In general, practice units in the CH-PSC relate to hands-on work or technology, for example: '[Students learn to] use common materials to make simple tools' (CH-PSC, p. 37). The daily application of scientific knowledge is emphasised more in the FIN-PSC, for example: 'In health education, it is essential to understand the factors in the environment and in human activities that support and protect health and promote the development of competence that supports health, well-being and safety' (FIN-PSC, p. 1).

\section{Different Emphasis on Scientific Knowledge and Subject Area Categories}

All three types of scientific knowledge — content, procedural and epistemic — appear in both curricula. A similar pattern of emphasis is placed on these scientific knowledge types in both curricula. Content knowledge constitutes the most sizeable part, followed by procedural knowledge. The amount dedicated to epistemic knowledge is low. It should be noted that epistemic knowledge involves a higher level of knowledge in science and is difficult for younger students to understand.

Examples of content, procedural and epistemic scientific knowledge are provided below. Content knowledge: [Students should] have a basic knowledge of the components of plants and animals; know the life cycle of plants (CH-PSC, p. 5).

Procedural knowledge: Students will participate and interact in planning and carrying out simple research projects (FIN-PSC, p. 4).

Epistemic knowledge: Students will critically evaluate information sources and viewpoints (FIN-PSC, p.7). 
There is a statistically significant difference between the two curricula regarding the distribution of scientific knowledge categories, $\chi^{2}(2, N=1055)=52.3, p<0.05$ (Table 3$)$. The number of statements on content knowledge in the $\mathrm{CH}-\mathrm{PSC}$ is three times greater than that on procedural knowledge (74.7\% vs. $23.3 \%$ ). By contrast, the corresponding percentage in the FINPSC is almost equal to that for knowledge (52.8\% vs. 46.2\%). A possible explanation for this relates to the structure of the curricula as the CH-PSC is written in a more concrete and detailed way. Another reason pertains to the distribution of the scientific competencies in each curriculum. The 'inquiry' domain in the CH-PSC does not receive as much attention as that in the FIN-PSC. This competency usually requires both procedural and content knowledge. Fulfilment of the 'explain' competency, associated with a high percentage in the CH-PSC, usually involves the application of content knowledge, for example: 'Describe the motion of objects' and 'Give examples of how animals connect with the environment'.

Table 3. Frequency of scientific knowledge (percentage)

\begin{tabular}{lccc}
\hline Scientific knowledge & CH-PSC & FIN-PSC & Total \\
\hline Content knowledge & $565(74.7 \%)$ & $158(52.8 \%)$ & 723 \\
Procedural knowledge & $176(23.3 \%)$ & $138(46.2 \%)$ & 314 \\
Epistemic knowledge & $15(2.0 \%)$ & $3(1.0 \%)$ & 18 \\
Total & 756 & 299 & 1055 \\
\hline
\end{tabular}

$\chi^{2}(2, N=1055)=52.3, p<0.05$

There is a statistically significance between the two curricula regarded the relative number of statements pertaining to the different content areas, $\chi^{2}(3, N=723)=20.9, p<0.05$ (Table 4). The CH-PSC reads, 'Eighteen core ideas are chosen from four disciplinary areas: six from the physical sciences; six from the life sciences; three from the earth and space sciences and three from technology and engineering' (p. 10). Alignment with the declared division of the content in the curriculum (as detailed above) was seen following analysis of the distribution of 
the content areas in the CH-PSC. By contrast, there is no stated instruction regarding the division of aims based on the subject areas in the FIN-PSC. Instead, the content is organised according to themes, with examples provided. There is emphasis on living and physical systems in the FINPSC.

Table 4. Frequency of content knowledge (percentage)

\begin{tabular}{lccc}
\hline Content knowledge & CH-PSC & FIN-PSC & Total \\
\hline Physical systems & $201(35.6 \%)$ & $52(32.9 \%)$ & 253 \\
Living systems & $144(25.5 \%)$ & $68(43.0 \%)$ & 212 \\
Earth and space systems & $111(19.7 \%)$ & $24(15.2 \%)$ & 135 \\
Technology and engineering system & $109(19.3 \%)$ & $14(8.9 \%)$ & 123 \\
Total & 565 & 158 & 723 \\
\hline
\end{tabular}
$\chi^{2}(3, N=723)=20.9, p<0.05$

\section{Small Differences in Emphasis on Attitudes to Science}

The distribution of attitudes to science in the two curricula is illustrated in Table 5. In general, attitudes not only cover students' learning experiences (the learning process), for example their interest in learning science, but also their learning outcomes, for example the disposition of scientific approaches to enquiry and environmental awareness. The identification of two approaches to attitudes to science suggests that attitudes were considered to be both a means to an end and an end in itself in both curricula. Moreover, analysis of the curriculum statements showed that both curricula place considerable emphasis on the 'interest' aspect of science and particularly on nurturing the development of positive feelings in students when learning science. There is also a high percentage of statements on the 'disposition of scientific approaches to enquiry' in both the CH-PSC and FIN-PSC (32.3\% and 29.1\%, respectively), as well on 'environmental awareness' $(25.0 \%$ vs. $34.6 \%)$. Surprisingly, the FIN-PSC does not include a statement on 'ethics in science'. Although this code has a low rating in the CH-PSC, it 
is nevertheless included: 'Students should know that in science and technology research and application, ethics and moral issues should be considered seriously' (p. 9).

Table 5. Frequency of attitudes to science (percentage)

\begin{tabular}{lccc}
\hline Attitudes to science & CH-PSC & FIN-PSC & Total \\
\hline Interest in science & $37(29.8 \%)$ & $14(25.5 \%)$ & 51 \\
Self-concept or self-efficacy & $11(8.9 \%)$ & $6(10.9 \%)$ & 17 \\
Disposition of scientific & $40(32.3 \%)$ & $16(29.1 \%)$ & 56 \\
approaches to enquiry & $31(25.0 \%)$ & $19(34.6 \%)$ & 50 \\
Environmental awareness & $5(4.0 \%)$ & $0(0 \%)$ & 5 \\
Ethics in science & 124 & 55 & 179 \\
Total & &
\end{tabular}

$\chi^{2}(4, N=179)=2.1, p=0.71$

Differences in the distribution of attitudes to science across the countries were without statistical significance, $\chi^{2}(4, N=179)=2.1, p=0.71$. However, the statements, as qualitative data, indicated differences between the curricula. These differences confirm that the hypothesis that the curricula were written from different viewpoints and indicate affiliation differences regarding the theories of curriculum. The hypothesis is exemplified with the following quotations.

Interest in science: '[S]tudents should remain curious about natural phenomena and remain passionate about enquiry' (CH-PSC, p. 8).

'[Teachers should $]$ attract and deepen the students' interest in the various fields of environmental studies' (FIN-PSC, p. 1).

Self-concept or self-efficacy: '[Students should learn to] overcome difficulties during research and complete the scheduled tasks' (CH-PSC, p. 8).

'[Teachers should] recognise students' competence in environmental studies and [support the students to] make persistent efforts to achieve [personal study goals]' (FIN-PSC, p. 6). 
Disposition of scientific approaches to enquiry: 'Students should develop an awareness that they must present their ideas based on evidence and proper reasoning' (CH-PSC, p. 8).

'The student should be encouraged to wonder and ask questions...' (FIN-PSC, p. 2). Environmental awareness: "[Students should] formulate an awareness to protect the environment and take social responsibility...' (CH-PSC, p. 8).

'[Teachers should] support the development of the students' environmental awareness' (FIN-PSC, p. 2).

Many of the objectives begin with either 'student' or 'teacher'. Accordingly, the statements reflect the different perspectives of writing a national curriculum and the role of the intended curriculum in the teaching approach. The CH-PSC focuses on the students' performance without explicitly accentuating the teacher's role as a facilitator in actualising the class objectives. A converse stance is adopted in the FIN-PSC. Statements from the FIN-PSC clarify the supportive role played by teachers, especially with regard to the development of attitudes, even when the objectives pertain to the behaviour or attitudes expected of the students.

\section{Learning Contexts in the Curricula}

By taking the scientific learning experiences of the students into consideration and endeavouring to cultivate scientifically literate citizens, each curriculum has contextualised the learning experience. When the total number of units is calculated, the FIN-PSC is shown to refer to learning contexts (about 1:2) more often than that in the CH-PSC (about 1:3) (253 units in the 'learning context' plus 530 units in scientific literacy vs. 332 units in the 'learning context' plus 1154 units in scientific literacy, respectively). 
Topics that relate to the twenty-first century are illustrated in the framework, for example, environmental quality is considered in both curricula, implying modernisation in both. However, the difference in the distribution of categories relating to the learning context is statistically significant, $\chi^{2}(4, N=173)=20.9, p<0.05$. 'Natural resources and technology' $(N=$ $37,36.6 \%)$ and 'environmental quality' $(N=41,40.6 \%)$ constitute the topics of learning contexts that have emphasis in the CH-PSC. The corresponding areas in the Finnish primary science curriculum are 'health and disease' $(N=32,44.4 \%)$ and 'environmental quality' $(N=24,33.3 \%)$ (Table 6).

Table 6. Frequency of the learning contexts (percentage) in topics

\begin{tabular}{lccc}
\hline Learning contexts in topics & CH-PSC & FIN-PSC & Total \\
\hline Health and disease & $13(12.9 \%)$ & $32(44.4 \%)$ & 45 \\
Natural resources and & $37(36.6 \%)$ & $12(16.7 \%)$ & 49 \\
technology & $41(40.6 \%)$ & $24(33.3 \%)$ & 65 \\
Environmental quality & $6(5.9 \%)$ & $2(2.8 \%)$ & 8 \\
Hazards & $4(4.0 \%)$ & $2(2.8 \%)$ & 6 \\
Frontiers of science and & 101 & 72 & 173 \\
technology & & & \\
Total & &
\end{tabular}
$\chi^{2}(4, N=173)=20.9, p<0.05$

The 'perspectives' domain refers to the perspective from which science instruction is offered. Typically, 'daily life' reflects the 'personal' level, 'nature' reflects the 'local' level and 'earth' reflects the 'global' level. Thus, the learning contexts differ accordingly. Based on the quantitative findings of the current research, it is evident that the students' learning experiences were thoughtfully considered in close relation to life at personal and local levels in both curricula. The difference between the curricula regarding the distribution of subcategories from a learning context perspective is statistically significant, $\chi^{2}(2, N=412)=27.6, p<0.05$. The personal level $(N=100,43.3 \%)$ and the global level $(N=88,38.1 \%)$ receive the most emphasis in the CH-PSC, whereas the personal level $(N=82,45.3 \%)$ and the local level $(N=68,35.6 \%)$ are 
valued most in the FIN-PSC (Table 7). This implies that both curricula are based on students' experiences and seek to connect the teaching content to a concrete personal and local context. The FIN-PSC appears to be concerned with the local environment and a discussion of student living communities in Finland. The CH-PSC discusses large topics at the global level, relating them to the development of the earth and human beings.

Examples of learning contexts in the curricula are provided below.

Personal: The material in the primary science curriculum is selected from the students' daily lives and natural phenomena (CH-PSC, pp. 2-3).

Local and global: Guide the pupil in geographical thinking, to perceive his or her own environment and the entire world (FIN-PSC, p. 7).

Table 7. Frequency of learning contexts (percentage) in perspectives

\begin{tabular}{lccc}
\hline Learning contexts in perspectives & CH-PSC & FIN-PSC & Total \\
\hline Personal & $100(43.3 \%)$ & $82(45.3 \%)$ & 182 \\
Local & $43(18.6 \%)$ & $68(37.6 \%)$ & 111 \\
Global & $88(38.1 \%)$ & $31(17.1 \%)$ & 119 \\
Total & 231 & 181 & 412 \\
\hline
\end{tabular}

$\chi^{2}(2, N=412)=27.6, p<0.05$

\section{Discussion}

Scientific literacy (SL) aims, established for primary school science education in the national curricula of China and Finland, were evaluated and compared in the current study. Generally, the SL objectives appear to be integrated in both curricula, with nearly equal coverage of the categories and subcategories, identified using a revised PISA analytical framework. This suggests that the objectives of the two curricula are in line with those of the PISA framework. Based on the quantitative results, the tendencies are similar in general, even if the emphasis in the subcategories varies. Knowledge forms the main body of each curriculum, followed by competencies and attitudes, and then learning contexts. However, there are differences in the 
way in which the curricula are written. The following discussion is based on three visions of SL and the perspectives of two curriculum traditions, Bildung-Didaktik and Anglo-American.

The Chinese and the Finnish curricula emphasise that knowledge and competencies are required to achieve scientific knowledge and promote attitude development and learning contexts. The connection between scientific knowledge/competencies and attitudes within the learning contexts pertains to the integration of Roberts's Visions I and II in both curricula. Nonetheless, the Chinese curriculum leans more towards Vision I as its subheadings and content follow well-organised subject areas instead of topics that relate to science, and the general emphasis on each subcategory differs from that in the Finnish curriculum. For example, the Chinese curriculum does not mention learning contexts as often as the Finnish curriculum.

SL aims from the perspective of Vision III do not explicitly appear in either curriculum although there is a vague mention of intention in this direction. The core tasks for science education in the two curricula differ with respect to terms. Preference is given to 'sustainable development' or 'well-being' in the Finish curriculum, whereas 'scientific literacy' is favoured in the Chinese curriculum. The core task of 'sustainable development' in the Finnish curriculum infers aims beyond science (i.e., the 'ecological, cultural, social and economic dimensions of sustainable development') and the desire for each individual to fulfil his or her potential. Nevertheless, the phrase 'sustainable development' is potentially problematic owing to its ambiguous nature. For example, it could be based on goals of economic development, where individuals are seen as human capital (Hodson, 2011). Hence, in the absence of an open discussion on the complex socio-political context and a clear explanation of vocabulary such as 'sustainable development' or 'well-being', it is difficult to determine whether or not the Finnish curriculum explicitly endorses the Vision III aims (Bazzul, 2012; Sjöström et al., 2017). 
Similarly, the core task of the Chinese curriculum is to develop SL. Emphasis is also placed on the cultivation of citizens who will actively engage in social and political issues. However, the discourse as a whole and the fundamental existence of primary science as a subject is based on the important roles of science and technology in social and economic development, implying that market logic is taken for granted without science founded on socio-political participation. Moreover, although it is demonstrated through analysis that the objective of both curricula is that students should participate in SSIs, the underlying discourse seems to be based on limited democratic participation. For example, the quantitative data show emphasis in each curriculum on attitudes such as environmental awareness, yet a clear statement of aims is not included that would allow the students to determine their own solutions regarding how to participate in or address environment issues, nor are the complicated contexts of economic development and policy-making in dealing with the environment taken into account. Even if the learning contexts for SSI topics in each curriculum are addressed from a quantitative perspective, qualitatively, the context descriptions do not reflect the complex economic, ethical and political issues that affect science and science education. The fleeting inclusion of Vision III could relate to the nature of the curriculum, thus only permitting a hint at the adoption of an SSI approach, rather than clearly addressing the topic. The scarcity of this component (Vision III) is understandable because the curricula target primary schoolchildren. Our argument is not to add new objectives that would exhaust the students' abilities at such an early age. Nevertheless, a possible recommendation is that Vision III should be recognised by the teachers. If the curriculum was written to explicitly include this vision, the teachers would be able to organise classes with larger, reflective views and would be able to educate students with this in mind. 
In terms of the different traditions under consideration, our results show that the Finnish curriculum integrates the Bildung-Didaktik and Anglo-American features. For example, while scientific knowledge constitutes a major portion of the curriculum, a concrete or carefully structured list of contents is absent from the Finnish curriculum, which primarily includes broad thematic content. Indeed, the objectives for subject content are seldom fully specified; instead, the aims are presented in conjunction with sample objectives. While the Finnish curriculum that is formulated from the instructional perspective of the teacher is a feature of the Didaktik tradition, objectives for learner-based performance are characteristic of the Anglo-American tradition. In contrast, the Chinese curriculum formulates its aims by specifying detailed objectives to inform the learning outcomes of students, thus favouring the Anglo-American tradition.

Compared to the single-minded focus of the Chinese curriculum, which is based on competencies needed in the future to support social and economic development, the objective of the Finnish curriculum encompasses 'developing a world view' and 'growing as human beings', indicating the importance of individual fulfilment and the transformation of society through learning science; therefore in alignment with the Bildung tradition. However, the Finnish curriculum lacks any mention of the subcategory 'ethics in science' in the 'attitudes to science' category, which might weaken the argument of its affiliation with that tradition.

Our findings have implications for the design of science curriculum. Firstly, regardless of what appears to be the core task in a national science curriculum, it is important to clearly articulate the meaning behind the task and consistently integrate the organised aims into the curriculum. Secondly, the findings suggest weakness in the Vision III perspective, which is primarily needed in the context of neoliberalism, where people take things for granted, follow the 
belief in the importance of the economy and view education as a means of developing future human capital. This view is in opposition to the ultimate educational goal because moral and ethical aspects are overlooked. With regard to science education, learning science is considered to be an end in itself. This position tends to overlook general educational aims when learning science, such as education for the purpose of sustainability.

This study had a number of limitations. Firstly, it was limited by a lack of information on the implemented curriculum which could have affected the quantitative results and ensuing discussion. Because each unit could not be equal in terms of importance and teaching time, the research quantitative data, which are based on the frequencies of the units without being weighted, could only indicate the tendencies of the intended curriculum. Secondly, the current study examined the latest curricula published in two countries. At most, this can only reflect the current situation owing to the absence of a historical perspective on changes to the curricula. Thirdly, perceptions of SL and its components may be limited because the analytical framework derives from PISA, which is administered by a market economy-based body, namely OECD (Addey, Sellar, Steiner-Khamsi, Lingard \& Verger, 2017). Given the nature of the OECD, policy-makers and industry influence on science, PISA assessment could have been interpreted as neutral and might have been taken for granted in general, with positive suggestions for economic development. Finally, content analysis was used in the current study and this method might have limited insight into the impact of ideological influences, such as neoliberalism, on the national curriculum. 


\section{References}

Addey, C., Sellar, S., Steiner-Khamsi, G., Lingard, B., \& Verger, A. (2017). The rise of international large-scale assessments and rationales for participation. Compare: A Journal of Comparative and International Education, 47(3), 434-452. doi:10.1080/03057925.2017.1301399

Apple, M. W. (1993). The politics of official knowledge: Does a national curriculum make sense? Discourse: Studies in the Cultural Politics of Education, 14(1), 1-16.

[Author(s), year]

[Author(s), year]

Autio, T. (2014). The internationalization of curriculum research. In W. Pinar (Ed.), International Handbook of curriculum research (pp. 17-31). New York, NY: Routledge.

Bazzul, J. (2012). Neoliberal ideology, global capitalism, and science education: Engaging the question of subjectivity. Cultural Studies of Science Education, 7(4), 1001-1020.

Bergqvist, E. \& Bergqvist, T. (2017). The role of the formal written curriculum in standardsbased reform. Journal of Curriculum Studies, 49(2), 149-168.

Britton, E., D. \& Schneider, S. A. (2014). Large-scale assessments in science education. In S. K. Bell, N. G. Lederman (Eds.), Handbook of Research on Science Education (pp. 791-810). New York: Routledge.

Bybee, R. \& McCrae, B. (2011). Scientific literacy and student attitudes: Perspectives from PISA 2006 science. International Journal of Science Education, 33(1), 7-26.

Cuban, L. (1992). Curriculum stability and change. In P. W. Jackson (Ed.), Handbook of Research on Curriculum (pp. 216-247). New York, NY: Macmillan. 
Cuban, L. (2013). Why so many structural changes in schools and so little reform in teaching practice? Journal of Educational Admin, 51(2), 109-125. doi:10.1108/09578231311304661

De Boer, G. E. (2000). Scientific literacy: Another look at its historical and contemporary meanings and its relationship to science education reform. Journal of Research in Science Teaching, 37(6), 582-601.

De Boer, G. E. (2011). The globalization of science education. Journal of Research in Science Teaching, 48(6), 567-591. doi:10.1002/tea.20421

Ding, B. P. (2015). Science education in mainland China. In R. Gunstone (Ed.), Encyclopedia of Science Education (pp. 882-889). Dordrecht: Springer Netherlands.

Donnelly, J. (2006). The intellectual positioning of science in the curriculum, and its relationship to reform. Journal of Curriculum Studies, 38(6), 623-640.

Fensham, P. J. (2009). The link between policy and practice in science education: The role of research. Science Education, 93(6), 1076-1095.

Finnish National Board of Education (2016). National core curriculum for basic education 2014. Helsinki: National Board of Education.

Fullan, M. G. (2001). The new meaning of educational change (3rd ed.). New York, NY: Teachers College Press.

Harlen, W. (2001). The Assessment of Scientific Literacy in the OECD/PISA Project. Studies in Science Education, 36(1), 79-103.

Hodson, D. (2003). Time for action: Science education for an alternative future. International Journal of Science Education, 25(6), 645-670. 
Hodson, D. (2011). Looking to the future: Building a curriculum for social activism. Rotterdam: SensePublishers.

Holbrook, J. \& Rannikmae, M. (2007). The nature of science education for enhancing scientific literacy. International Journal of Science Education, 29(11), 1347-1362.

Hopmann, S. (2007). Restrained teaching: The common core of Didaktik. European Educational Research Journal, 6(2), 109-124.

Krathwohl, D. R. (2002). A revision of Bloom's taxonomy: An overview. Theory into practice, 41(4), 212-218.

Law, W. (2014). Understanding China's curriculum reform for the 21 st century. Journal of Curriculum Studies, 46(3), 332-360.

Levinson, R. (2010). Science education and democratic participation: An uneasy congruence? Studies in Science Education, 46(1), 69-119. doi:10.1080/03057260903562433.

Mayring, P. (2015). Qualitative content analysis: Theoretical background and procedures. In Approaches to Qualitative Research in Mathematics Education (pp. 365-380). Springer Netherlands.

Niemi, H., Toom, A., \& Kallioniemi, A. (2016). Miracle of education: The principles and practices of teaching and learning in Finnish schools (2nd ed.). Rotterdam: Sense Publishers.

Oliva, P. (1997). The Curriculum: theoretical dimensions. New York: Longman.

Organisation for Economic Cooperation and Development. (2013). PISA draft science framework. Retrieved from OECD website: http://www.oecd.org/pisa/pisaproducts/Draft\%20PISA\%202015\%20Science\%20Framew ork\%20.pdf. 
Organisation for Economic Cooperation and Development (2016). PISA 2015 Results (Volume I): Excellence and equity in education. Paris: OECD Publishing.

Osborne, J. (2007). Science education for the twenty first century. Eurasia Journal of Mathematics, Science \& Technology Education, 3(3), 173-184.

Osborne, J. \& Collins, S. (2001). Pupils' views of the role and value of the science curriculum: A focus-group study. International Journal of Science Education, 23(5), 441-467.

Osborne, J., Simon, S. \& Collins, S. (2003). Attitudes towards science: A review of the literature and its implications. International Journal of Science Education, 25(9), 1049-1079.

Pantić, N. \& Wubbels, T. (2012). Competence-based teacher education: A change from Didaktik to curriculum culture? Journal of Curriculum Studies, 44(1), 61-87.

Roberts, D. A. (2007). Scientific literacy/science literacy. In S. K. Abell \& N. G. Lederman (Eds.), Handbook of research on science education (pp. 729-780). Mahwah, NJ: Lawrence Erlbaum Associates (LEA).

Roberts, D. B., Bybee, W. R. (2014). Scientific literacy, science literacy, and science education. In N. G. Lederman, S. K. Abel (Eds.), Handbook of research on science education (pp. 545-558). New York: Routledge.

Roth, K. J. (2014). Elementary science teaching. In N. G. Lederman, S. K. Abel (Eds.), Handbook of Research on Science Education (pp. 361-394). New York: Routledge.

Ryder, J. (2001). Identifying science understanding for functional scientific literacy. Studies in Science Education, 36(1), 1-44.

Saari, A., Salmela, S., \& Vilkkilä, J. (2014). Governing autonomy. In W. Pinar (Ed.), International Handbook of Curriculum Research (pp. 183-200). New York, NY: Routledge. 
Sadler, T. D., \& Zeidler, D. L. (2009). Scientific literacy, PISA, and socioscientific discourse: Assessment for progressive aims of science education. Journal of Research in Science Teaching, 46(8), 909-921.

Sahlberg, P. (2015). Finnish lessons 2.0: What can the world learn from educational change in Finland? (2nd ed.). New York: Teachers College Press.

Sjöström, J., Frerichs, N., Zuin, V., \& Eilks, I. (2017). Use of the concept of Bildung in the international science education literature, its potential, and implications for teaching and learning. Studies in Science Education, 53(2), 165-192.

doi:10.1080/03057267.2017.1384649

Tao, Y., Oliver, M., \& Venville, G. (2013). A comparison of approaches to the teaching and learning of science in Chinese and Australian elementary classrooms: Cultural and socioeconomic complexities. Journal of Research in Science Teaching, 50(1), 33-61.

Viera, A. J., \& Garrett, J. M. (2005). Understanding inter observer agreement: The kappa statistic. Family Medicine, 37(5), 360-363.

Weber, R. P. (1990). Basic content analysis: Quantitative applications in the social sciences $\left(2^{\text {nd }}\right.$ ed.). Thousand Oaks, CA, US: SAGE Publications, Inc.

Westbury, I. (2000). Teaching as a reflective practice: what might Didaktik teach curriculum? In S. Hopmann, K. Riquarts, \& I. Westbury (Eds.), Teaching as a reflective practice: the German Didaktik tradition. Mahwah, NJ: Lawrence Erlbaum Associates.

Willbergh, I. (2015). The problems of 'competence' and alternatives from the Scandinavian perspective of Bildung. Journal of Curriculum Studies, 47(3), 334-354.

doi:10.1080/00220272.2014.1002112 
Zhang, H. \& Gao, Z. (2014). Curriculum studies in China. In W. Pinar (Ed.), International Handbook of Curriculum Research (pp. 118-133). New York, NY: Routledge.

Ziman, J. (2000). Real science: What it is, and what it means. Cambridge: Cambridge University Press. 